\title{
Comparison of Aripiprazole and Other Atypical Antipsychotics for Pediatric Bipolar Disorder: A Retrospective Chart Review of Efficacy and Tolerability
}

\author{
Jooyoung Oh, Jhin Goo Chang, Seul Bi Lee, Dong-Ho Song, Keun-Ah Cheon \\ Division of Child and Adolescent Psychiatry, Department of Psychiatry and Institute of Behavioral Science in Medicine, Yonsei University \\ College of Medicine, Seoul, Korea
}

\begin{abstract}
Objective: This study compared the efficacy and tolerability of aripiprazole with that of other atypical antipsychotics by examining patients with pediatric bipolar disorder (PBD) at a child and adolescent psychiatric clinic in a university hospital in Korea. Methods: We reviewed the medical records of 127 pediatric patients with bipolar disorder aged 4-18 years treated at Department of Child and Adolescent Psychiatric, Yonsei University Severance Hospital between January 2010 and October 2011 to collect demographic and clinical data. Using the Clinical Global Impression (CGl) scales, we evaluated levels of severity of and improvements in symptoms at the first, second, third, fourth, and fifth hospital visits.

Results: The mean age of patients was $12.29 \pm 3.47$ years. The sample included 91 (71.7\%) male and $36(28.3 \%)$ female patients. Aripiprazole was prescribed to $62(48.8 \%)$ patients, risperidone to $52(40.9 \%)$, quetiapine to 11 (8.7\%), and paliperidone to two (1.6\%). Patients treated with aripiprazole had lower CGI-Severity (CGI-S) scores than did patients treated with other atypical antipsychotics at the second and third visits. The CGI-Improvement (CGI-I) scores of patients treated with aripiprazole were lower at the second visit. Treatment with atypical antipsychotics was well tolerated, and no serious or fatal side effects were observed.

Conclusion: The present retrospective chart review suggests that atypical antipsychotics may be effective and safe for the treatment of patients with PBD. In particular, treatment with aripiprazole may be more effective than treatment with other atypical antipsychotics in the early phase. These results should be verified in future multi-center controlled studies.
\end{abstract}

KEY WORDS: Bipolar disorder; Child psychiatry; Antipsychotic agents; Aripiprazole.

\section{INTRODUCTION}

Pediatric bipolar disorder (PBD) is characterized by a chronic and serious progression ${ }^{1)}$ and a poor prognosis. ${ }^{2)}$ Additionally, it has been reported that $50-66 \%$ of cases of adult bipolar disorder begin in childhood and adolescence. ${ }^{3)}$ PBD was previously considered to be rare. However, since the mood-related and behavioral features of PBD have come to be recognized as different from those of bipolar disorder in adults and as the importance of individual symptoms has been emphasized, PBD is now thought to be more common. Children and adolescents experience faster changes in mood and behavior than do

\footnotetext{
Received: February 1, 2013 / Revised: April 8, 2013

Accepted: April 12, 2013

Address for correspondence: Keun-Ah Cheon, MD, PhD

Division of Child and Adolescent Psychiatry, Department of Psychiatry and Institute of Behavioral Science in Medicine, Severance Hospital, Yonsei University College of Medicine, 50 Yonsei-ro, Seodaemun-gu, Seoul 120-752, Korea

Tel: +82-2-2228-1633, Fax: +82-2-313-0891

E-mail: kacheon@yuhs.ac
}

adults, and they sometimes also suffer from conditions such as attention deficit hyperactivity disorder (ADHD). Moreover, patients with childhood/adolescent-onset bipolar disorder have more manic and depressive episodes than do those with adult-onset bipolar disorder. ${ }^{4)}$ Psychopharmacotherapy is essential in the treatment of PBD, and mood stabilizers and atypical antipsychotics are currently the most frequently considered primary drugs for this purpose. ${ }^{5)}$ The combined administration of multiple agents has also been reported to be effective for bipolar disorder and concomitant conditions. ${ }^{6}$ Additionally, administration of either lithium or valproic acid in actual clinical cases has not been sufficiently effective for long-term treatment. ${ }^{7)}$ However, long-term use of combined agents presents a safety problem in children and adolescents. $^{8)}$

Among the various agents used for adult patients with bipolar disorder, atypical antipsychotics have been proven effective, ${ }^{9)}$ and exclusive use of these agents in children and adolescents has also been reported to be effective. ${ }^{10)}$

() This is an Open-Access article distributed under the terms of the Creative Commons Attribution Non-Commercial License (http://creativecommons.org/licenses/by-nc/3.0) which permits unrestricted non-commercial use, distribution, and reproduction in any medium, provided the original work is properly cited. 
Retrospective studies on the efficacy and safety of atypical antipsychotic agents, such as aripiprazole, for patients with PBD have been conducted in the US. ${ }^{11,12)}$ Doubleblind placebo-control studies on long-term maintenance treatment with aripiprazole in children and adolescents are also currently in process. ${ }^{13)}$

One of the atypical antipsychotics, aripiprazole, acts as a partial agonist at the dopaminergic D2 receptor and serotonin HT1A receptor and as an antagonist at the serotonin $5 \mathrm{HT} 2 \mathrm{~A}$ receptor. Because of these characteristics, aripiprazole has been known to have mild side effects and to be safe for pediatric patients suffering from such symptoms as tics. ${ }^{14)}$ In particular, the low sedating effect and low weight gain associated with this drug may make it easier for pediatric patients to function at school.

Thus, it is necessary to study the prescribing pattern, efficacy, and safety of aripiprazole and other atypical antipsychotics for pediatric patients. Indeed, extant research on the efficacy and safety of diverse agents for the treatment of PBD is not adequate. As far as we know, few studies on the patterns of administration to patients with PBD have been conducted in Korea, and no known study has compared the efficacy of each agent in Korean populations. The purpose of this study was to compare the efficacy and tolerability of aripiprazole with those of other atypical antipsychotics by investigating patients with PBD at a child and adolescent psychiatric clinic in a university hospital in Korea.

\section{METHODS}

Patients aged 4-18 years who received outpatient treatment at Department of Child and Adolescent Psychiatry, Yonsei University Severance Hospital (Seoul, Korea) between January 2010 and October 2011 were selected for inclusion in the present study. Chart reviews were conducted for the 183 patients who were screened through a search for bipolar I disorder, bipolar II disorder, bipolar disorder, and bipolar affective disorder. Of these 183 patients, those whose main reason for treatment was another diagnosis, such as tic disorder or ADHD, were excluded, as were those who visited the clinic only once or did not take mediation. After exclusion, 127 patients who were diagnosed by child psychiatrists with bipolar I disorder, bipolar II disorder, or bipolar disorder not otherwise specified according Diagnostic and Statistical Manual of Mental Disorders (DSM)-IV criteria were finally selected for participation in the present study. We also gathered demographic and clinical data including sex, age, in- telligence quotient (IQ), diagnosis, illness duration, concomitant diseases, types and dosages of atypical antipsychotics administered, treatment period, concomitant psychiatric illnesses, other agents administered, and side effects. Most patients with ADHD-like symptoms were assessed before and after treatment using the ADHD Rating Scale (ARS) to evaluate the severity of their symptoms. ${ }^{15)}$

Severity of and improvement in symptoms were evaluated prior to administration of atypical antipsychotics and at every visit using the Clinical Global ImpressionSeverity (CGI-S: $1=$ not ill, $7=$ extremely ill) and the CGIImprovement (CGI-I: 1=very much improved, 7=very much worse) scales. ${ }^{16)}$ The CGI scores of patients receiving aripiprazole were compared with those receiving other atypical antipsychotics (risperidone, quetiapine, paliperidone) at the first, second, third, fourth, and fifth hospital visits. The second visit followed the first by about 2 weeks, the third visit followed the second by about 1 month, the fourth visit followed the third by about 2 months, and the fifth visit followed the fourth by about 4 months. Data from patients who visited more than 1 week before or after the scheduled visit day were excluded from the analyses of that data point. We thereby excluded the data from three patients from analyses of the second visit, data from 14 patients from analyses of the third visit, data from 25 patients from analyses of the fourth visit, and data from 53 patients from analyses of the fifth visit. Owing to these missing data, we compared CGI scores using a linear mixed model.

\section{RESULTS}

The mean age of the 127 subjects with bipolar disorder was $12.29 \pm 3.47$ (ranging from 4 to 18 years of age); 53 subjects were younger than 12 years, and 74 were 12 years or older. The sample included $91(71.7 \%)$ male and 36 (28.3\%) female participants. The mean age of the male patients was $11.64 \pm 3.38$ years, which was significantly younger than that of the female patients, $13.94 \pm 3.39$ years $(p<0.01)$. The male and female patient groups did not differ in terms of duration of illness or IQ. Patients treated with aripiprazole did not differ significantly from those treated with other agents except that those receiving aripiprazole were significantly older than those receiving other medications (Table 1).

At the time of starting treatment, the mean illness duration of patients was $24.80 \pm 17.88$ months. The mean overall IQ was $91.75 \pm 20.88$; the mean verbal IQ was $95.14 \pm$ 
Table 1. Clinical characteristics of the subjects with aripiprazole versus with others

\begin{tabular}{|c|c|c|c|c|}
\hline Characteristic & Total $(n=127)$ & Aripiprazole $(n=62)$ & Others $(n=65)$ & $p$ value \\
\hline Age (year) & $12.29 \pm 3.47$ & $13.16 \pm 2.80$ & $11.46 \pm 3.95$ & $0.001^{*,+}$ \\
\hline Gender (male/female) & $91 / 36$ & $41 / 21$ & $50 / 15$ & $0.177^{\ddagger}$ \\
\hline \multicolumn{5}{|l|}{ Duration (month) } \\
\hline IIIness & $24.80 \pm 17.88$ & $26.23 \pm 20.08$ & $23.43 \pm 15.68$ & $0.114^{\dagger}$ \\
\hline Medication & $7.84 \pm 5.27$ & $8.24 \pm 5.90$ & $7.46 \pm 4.61$ & $0.410^{\dagger}$ \\
\hline $\mathrm{VIQ}$ & $95.14 \pm 21.49$ & $99.07 \pm 19.01$ & $91.74 \pm 23.26$ & $0.198^{\dagger}$ \\
\hline $\mathrm{PIQ}$ & $88.89 \pm 18.93$ & $91.46 \pm 18.09$ & $86.66 \pm 19.70$ & $0.891^{\dagger}$ \\
\hline $\mathrm{TIQ}$ & $91.75 \pm 20.88$ & $95.14 \pm 18.52$ & $88.62 \pm 22.76$ & $0.300^{\dagger}$ \\
\hline
\end{tabular}

Values are presented as mean \pm standard deviation, or number

${ }^{*} p<0.01 .{ }^{+}$student t-test, ${ }^{\dagger}$ chi-square test.

$\mid Q$, intelligence quotient; $V \mid Q$, verbal $\mid Q ; P I Q$, performance $1 Q ; T I Q$, total $1 Q$.

Table 2. Mean dose and medication duration of atypical antipsychotics

\begin{tabular}{lccc}
\hline & Aripiprazole & Risperidone & Quetiapine \\
\hline Mean dose (mg) & $9.58 \pm 5.38$ & $1.46 \pm 1.08$ & $207.46 \pm 200.53$ \\
Medication duration (month) & $8.24 \pm 5.90$ & $7.50 \pm 4.12$ & $7.27 \pm 6.86$ \\
\hline
\end{tabular}

Values are presented as mean \pm standard deviation.

Atypical drug type treated

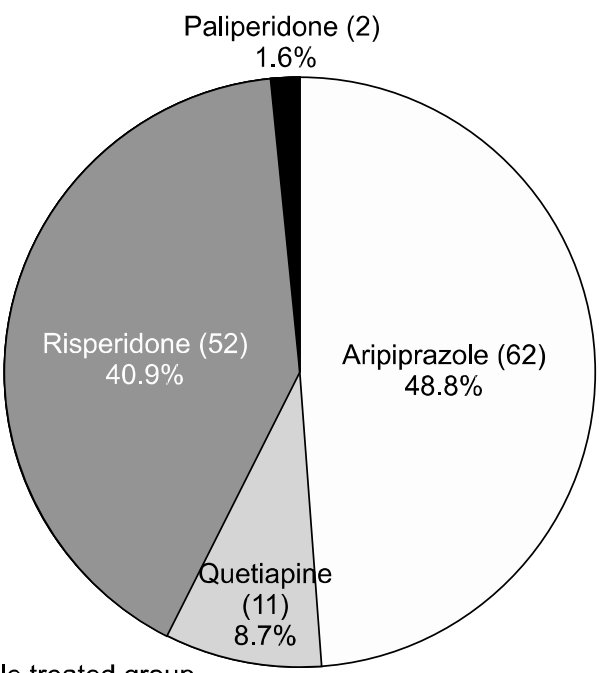

Aripiprazole treated group

Quetiapine treated group

Risperidone treated group

Paliperidone treated group

Fig. 1. Type of atypical antipsychotics used for pediatric bipolar disorder.

21.49 , and the mean performance IQ was $88.89 \pm 18.93$.

The mean drug administration period, defined as the period from when the primary agent was selected through the time the drug was continuously administered, was $7.8 \pm 5.3$ months. Aripiprazole was administered to 62 (48.8\%) patients as the major agent, risperidone to 52 (40.9\%), quetiapine to $11(8.7 \%)$, and paliperidone to two (1.6\%) (Fig. 1). Of the 127 patients, 10 received two atyp-
Table 3. Comorbidity of the bipolar subjects

\begin{tabular}{lc}
\multicolumn{1}{c}{ Comorbidity } & Data \\
\hline None & $43(33.9)$ \\
ADHD & $50(39.4)$ \\
Tic related disorders & $17(13.4)$ \\
Conduct disorder and ODD & $5(3.9)$ \\
Autism spectrum disorder & $12(9.4)$ \\
\hline
\end{tabular}

Values are presented as number (\%).

ADHD, attention deficit hyperactivity disorder; ODD, oppositional defiant disorder.

ical antipsychotics simultaneously, but identification of the major agent was not difficult (e.g., quetiapine, at 700 $\mathrm{mg}$, was the major agent and risperidone, at $1 \mathrm{mg}$, was also prescribed). One patient was treated with $20 \mathrm{mg}$ of aripiprazole and $4 \mathrm{mg}$ of risperidone at the last visit, but this individual had been started at $20 \mathrm{mg}$ aripiprazole and had slowly added risperidone; therefore, aripiprazole was identified as the major agent. The mean dose and medication duration of aripiprazole were $9.58 \pm 5.38 \mathrm{mg}$ and $8.24 \pm 5.90$ months, respectively. In terms of chlorpromazine-equivalent doses, aripiprazole was administered at higher doses than were other agents, and aripiprazole was administered for about a month longer than were other agents (Table 2).

Forty-three $(33.9 \%)$ patients did not have a comorbid disorder, whereas 84 (66.1\%) did. Fifty (39.4\%) patients also met criteria for ADHD, and 17 (13.4\%) had tic-related disorders. Five $(3.9 \%)$ patients had conduct disorders or oppositional defiant disorders. Additionally, 12 
(9.4\%) patients were diagnosed with autism spectrum disorders (Table 3 ).

Mood stabilizers such as valproic acid were additionally administered to $20(15.7 \%)$ patients, methylphenidate to $34(26.8 \%)$, atomoxetine to $12(9.4 \%)$, and antidepressants to 27 (21.3\%) (Table 4).

The ARS was administered to 70 patients before and after treatment; the mean ARS score before treatment was 24.9 \pm 11.4 , and the mean ARS score after treatment was $13.1 \pm 5.5(\mathrm{t}=13.86, \mathrm{df}=69, p<0.001)$. The scores of 55 male patients changed from $25.0 \pm 9.5$ to $13.4 \pm 4.7$, and those of 15 female patients changed from $24.5 \pm 17.3$ to 12.07 \pm 8.0 (Fig. 2A). Before treatment, the mean ARS

Table 4. Concomitant medication of the bipolar subjects

\begin{tabular}{cl}
\hline Concomitant medication & \multicolumn{1}{c}{ Data } \\
\hline Mood stabilizers & $20(15.7)$ \\
Methylphenidate & $34(26.8)$ \\
Atomoxetine & $12(9.4)$ \\
Antidepressants & $27(21.3)$ \\
\hline
\end{tabular}

Values are presented as number (\%).

\section{A}
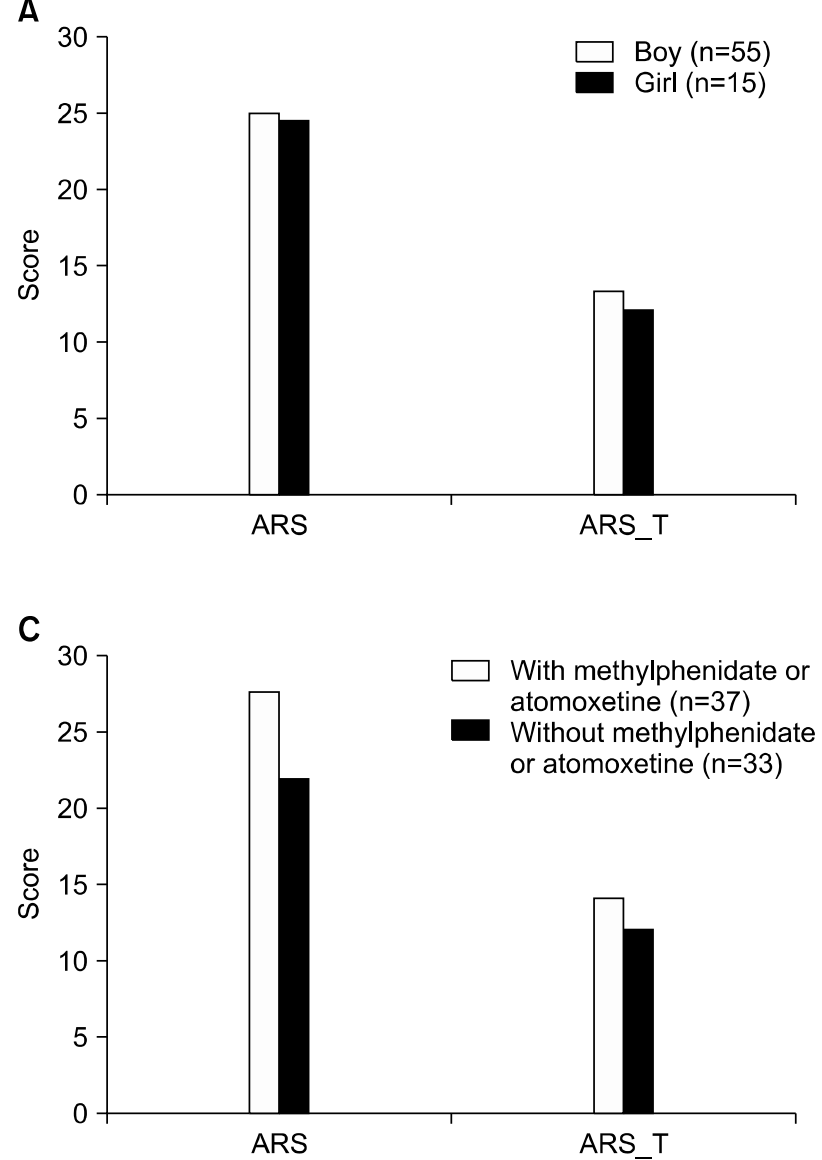

score of 39 patients with ADHD was 28.59 \pm 9.25 , which was significantly higher than that of patients without ADHD, 20.26 \pm 12.42 . After treatment, the mean ARS score of patients with ADHD was 14.62 \pm 4.03 , and that of patients without ADHD was $11.16 \pm 6.57$, reflecting that these scores were still significantly higher in those with ADHD (Fig. 2B). Before treatment, the mean ARS score of 37 patients receiving methylphenidate or atomoxetine was 27.54 \pm 10.65 ; their mean ARS score after treatment was $14.05 \pm 5.10$. The mean ARS score of 33 patients who were not receiving ADHD medications changed from $21.94 \pm 11.79$ to $12.00 \pm 5.88$ (Fig. $2 \mathrm{C}$ ).

Figs 4, 5 show comparisons between patients administered aripiprazole and those administered other atypical antipsychotics in terms of CGI-S and CGI-I scores at the first, second, third, fourth, and fifth hospital visits. Although many subjects participated in the entire testing process, three patients missed the second visit (about 2 weeks after the first visit), 14 missed the third visit (about 1 month after the second visit), 25 missed the fourth visit (about 2 months after the third visit), and 53 missed the fifth visit (about 4 months after the third visit).

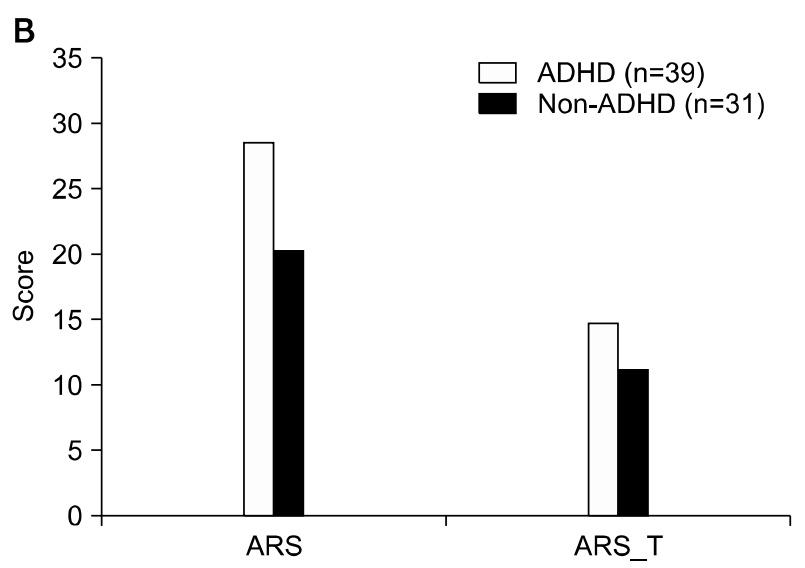

Fig. 2. (A) Effects on the attention deficit hyperactivity disorder (ADHD) rating scale scores of boys and girls by treatment. (B) Effects on ADHD rating scale scores of ADHD and non-ADHD by treatment. (C) Effects on $A D H D$ rating scale scores of groups with ADHD medications and groups without ADHD medications by treatment.

ARS, total score of ADHD rating scale; ARS_T, total score of $A D H D$ rating scale after treatment.

By paired t-test. $(t=13.86, d f=69, p<0.001)$. 
The mean period of administering aripiprazole (8.2 \pm 5.9 months) was longer than that of administering other atypical antipsychotics (7.5 \pm 4.6 months), but this difference was not significant $(p=0.410)$.

The CGI-S scores of the two groups did not differ at the first hospital visit, but those receiving aripiprazole scored lower on the CGI-S than did those receiving atypical antipsychotics at the second and third visits. No betweengroup differences in CGI-S scores were observed at the fourth or fifth hospital visit. Although the differences did not reach significance, CGI-S scores increased slightly in the group treated with other atypical antipsychotics, and they were higher in this group than in the group treated with aripiprazole at the fifth visit (Fig. 3). Scores on the CGI-I were compared at the second visit and at every subsequent visit. The CGI-I scores of those receiving aripiprazole were significantly lower than those receiving other medications at the second visit, indicating more improvement in the former than in the latter. No significant differences between the groups were observed after the second visit (Fig. 4).

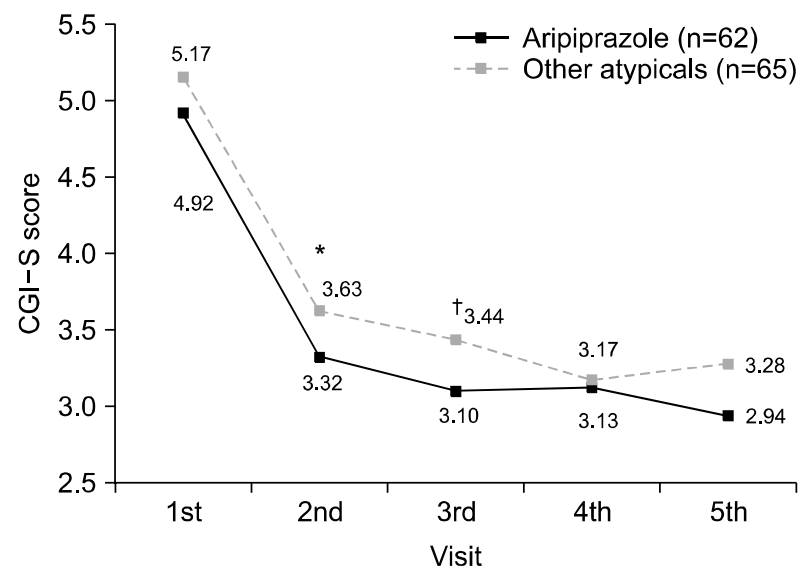

Fig. 3. Comparison of Clinical Global Impression-Severity (CGI-S) score between aripiprazole and other atypical antipsychotics by visit. By linear mixed model, post-hoc analysis; ${ }^{*} p<0.05,{ }^{\dagger} p<0.005$.
Thirty-seven (59.7\%) of 62 patients administered aripiprazole reported no side effects, whereas $13(21.0 \%)$ reported rigidity, five $(8.1 \%)$ reported akathisia, one $(1.6 \%)$ reported sedation, and four $(6.5 \%)$ reported increased appetite. Thirteen $(25.0 \%)$ of 52 patients administered risperidone reported no side effects, whereas four $(7.7 \%)$ reported rigidity, three $(5.8 \%)$ reported akathisia, two $(3.8 \%)$ reported sedation, and $24(46.2 \%)$ reported increased appetite. One $(9.1 \%)$ of 12 patients administered quetiapine reported no side effects, whereas one (9.1\%) reported rigidity, one $(9.1 \%)$ reported akathisia, one $(9.1 \%)$ reported sedation, and seven $(63.6 \%)$ reported increased appetite (Table 5).

\section{DISCUSSION}

This retrospective chart review of patients with PBD found that atypical antipsychotics, such as aripiprazole, reduced the severity of and contributed to improvements in clinical symptoms. At least $40 \%$ of patients reported no side effects associated with atypical antipsychotics, and

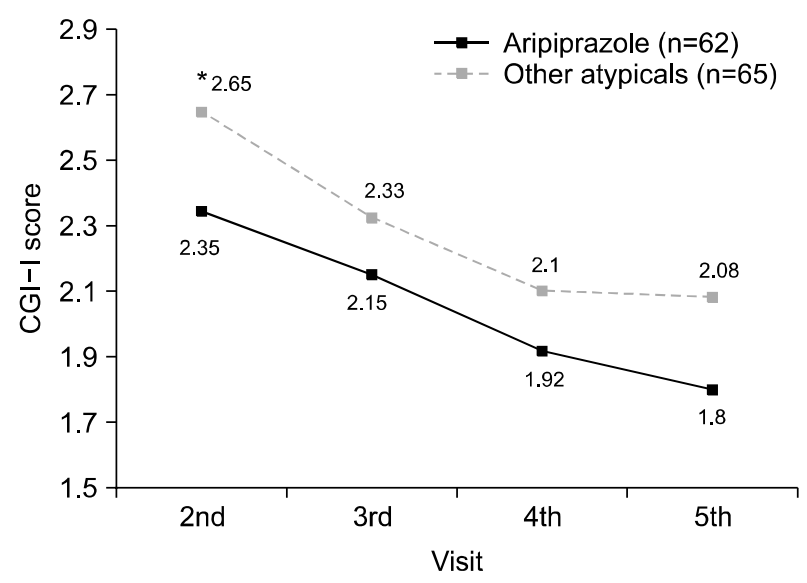

Fig. 4. Comparison of Clinical Global Impression-Improvement (CGI-I) score between aripiprazole and other atypical antipsychotics by visit.

By linear mixed model, post-hoc analysis; ${ }^{*} p<0.05$.

Table 5. Side effects of atypical antipsychotics

\begin{tabular}{|c|c|c|c|c|}
\hline Side effect & Aripiprazole & Risperidone & Quetiapine & Paliperidone \\
\hline None & $37(59.7)$ & $13(25.0)$ & $1(9.1)$ & $1(50.0)$ \\
\hline Rigidity & $13(21.0)$ & $4(7.7)$ & $1(9.1)$ & $0(0)$ \\
\hline Akathisia & $5(8.1)$ & $3(5.8)$ & $1(9.1)$ & $0(0)$ \\
\hline Sedation & $1(1.6)$ & $2(3.8)$ & $1(9.1)$ & $0(0)$ \\
\hline Appetite increase & $4(6.5)$ & $24(46.2)$ & $7(63.6)$ & $0(0)$ \\
\hline Others (nausea, dizziness) & $2(3.2)$ & $6(11.5)$ & $0(0)$ & $1(50.0)$ \\
\hline
\end{tabular}

Values are presented as number (\%). 
the remaining patients found the side effects they experienced to be comparatively tolerable. Additionally, with the exception of increased appetite, no significant differences were found among the agents used in terms of side effects.

The age and sex distributions of the patients included in this study were similar to those in previous studies. ${ }^{17-19)}$ The number of male patients treated for PBD was more than double that of female patients, and the mean age of male patients was younger than that of female patients. ${ }^{20)}$ These results are consistent with those of previous studies reporting that bipolar disorder develops earlier in males than in females. Other than age, no significant differences were found between male and female patients.

In the present study, $66.1 \%$ of all patients had concomitant conditions such as ADHD or tic-related disorders. This figure is lower than the $90 \%$ or more of patients who had ADHD in previous studies, and the prevalence of comorbid disruptive disorder was also lower than that in the prior research. ${ }^{21,22)}$ The prevalence of autism spectrum disorders was $9.4 \%$, which is also lower than the $15 \%$ reported in previous studies. ${ }^{23)}$ As the medications were administered for a mean of only 7.8 months in the present study, it is possible that insufficient consideration was given to the identification of concomitant disorders in this outpatient population. Indeed, symptoms that are common to mania, ADHD, and disruptive disorders may have led to differences among studies in the diagnosis of comorbid conditions. Additionally, we devoted insufficient attention to patients with two or more concomitant disorders. Originally, comorbid ADHD was identified in 50 patients; however, 70 patients completed the ARS before and after treatment with atypical antipsychotics, and the scores of these patients decreased by nearly 10 points, which indicates improvement. In particular, similar to patients treated with methylphenidate or atomoxetine, patients who were not treated with ADHD medications also showed substantial improvements in their ADHD symptoms. Even though we cannot determine whether their improvement was due to the atypical antipsychotics or to other medications, such as mood stabilizers, the atypical antipsychotics may have had some influence on the ADHD symptoms. In fact, psychostimulants are commonly used to treat ADHD, which is commonly found in patients with PBD and which may cause exacerbation of manic symptoms. For this reason, research has examined the additional use of atypical antipsychotics to improve manic symptoms and ADHD. ${ }^{24)}$ In the present study, 46 patients received methylphenidate and atomoxetine in ad- dition to atypical antipsychotics. Although some patients did not complete the ARS, improvements in the symptoms of both bipolar disorder and ADHD were confirmed, and this result is consistent with those of previous studies.

In the present study, use of aripiprazole and other atypical antipsychotics was shown to improve CGI-I and CGI-S scores. The CGI-S scores of the group treated with aripiprazole were lower than were those of the group treated with other agents at the second and third hospital visits, and the CGI-I scores of the aripiprazole group were also lower than were those of the other group at the second visit. This implies that the response to aripiprazole at the early stage of administration is better than that to other agents. Therefore, use of aripiprazole for early acute symptoms may be more effective than use of other agents. Additionally, although the difference was not statistically significant, at the fifth visit, the CGI-I and CGI-S scores of patients who received aripiprazole were lower were than those of patients who received agents other than aripiprazole. In view of the increase in the CGI-S scores between the fourth and fifth visits shown by patients receiving other atypical antipsychotics, it is possible that the long-term use of aripiprazole for maintenance treatment may also result in better outcomes. It should be noted, however, that many patients missed their fifth hospital visit, which may render these data invalid.

More than $40 \%$ of patients who were administered aripiprazole, risperidone, quetiapine, and paliperidone in the present study did not experience side effects, and absolutely no serious or fatal side effect was observed. As side effects such as rigidity, sedation, and akathisia were observed in less than $25 \%$ of subjects, use of atypical antipsychotics for patients with PBD is considered to be safe. Aripiprazole was expected to show fewer side effects compared with other agents, but no significant differences were found with regard to extrapyramidal symptoms and sedation. This may be due to an insufficient number of subjects and differences in dosages. The results show that aripiprazole and other agents had similar levels of side effects, but more favorable effects were obtained from aripiprazole compared with other agents. Moreover, aripiprazole was associated with lower rates of increased appetite than were other atypical antipsychotics. This strength of aripiprazole may enhance the compliance of pediatric patients.

This study had the following limitations. First, it used a retrospective design that relied on chart reviews. Thus, no placebo-control group was included, and the review process may have been biased because assessments of diag- 
noses, treatment effects, and side effects were made retrospectively based on charts. The reliance on chart reviews also precluded control of a sufficient number of population parameters, medication doses, concomitant medications, and comorbid disorders. Second, the intervals between hospital visits were not exactly consistent among patients, and this may have adversely affected our assessment of treatment effects. Third, the present study drew on patients at a single institution, and the number of subjects is too small to permit generalizations based on study results. Finally, insufficient consideration was given to concomitant conditions that are common among patients with PBD (e.g., anxiety disorders) during the review process, and side effects such as weight gain and hyperprolactinemia were also not completely assessed.

Despite these limitations, the present study used a naturalistic chart-review design that reflected actual prescribing patterns and yielded data on treatment effects and side effects from a clinical setting. Thus, it provides practical information that can be used for clinical purposes. Indeed, the present study provides useful information about PBD in patients in Korea. First, although the effects of agents administered in addition to antipsychotics, such as mood stabilizers, cannot be excluded, the use of atypical antipsychotics in Korean patients with PBD was confirmed as effective for improving the symptoms of bipolar disorder without leading to significant side effects. In particular, the early treatment effects and long-term tolerability of aripiprazole were found to be excellent compared with those of other atypical antipsychotics. The superior treatment effects of aripiprazole,${ }^{25)}$ which was also associated with comparatively mild side effects, may enhance the treatment compliance of pediatric patients and their guardians. However, these results must be confirmed in the future through multi-center, double-blind, placebo-control studies.

\section{Acknowledgments}

The authors wish to thank all other members of Department of Psychiatry and Institute of Behavioral Science in Medicine.

\section{REFERENCES}

1. Biederman J, Mick E, Faraone SV, Spencer T, Wilens TE, Wozniak J. Pediatric mania: a developmental subtype of bipolar disorder? Biol Psychiatry 2000;48:458-466.

2. Post RM, Leverich GS, Kupka RW, Keck PE Jr, McElroy SL, Altshuler LL, et al. Early-onset bipolar disorder and treatment delay are risk factors for poor outcome in adulthood. J Clin Psychiatry 2010;71:864-872.

3. Perlis RH, Miyahara S, Marangell LB, Wisniewski SR,
Ostacher M, DelBello MP, et al; STEP-BD Investigators. Long-term implications of early onset in bipolar disorder: data from the first 1000 participants in the systematic treatment enhancement program for bipolar disorder (STEP-BD). Biol Psychiatry 2004;55:875-881.

4. Leverich GS, Post RM, Keck PE Jr, Altshuler LL, Frye MA, Kupka RW, et al. The poor prognosis of childhood-onset bipolar disorder. J Pediatr 2007;150:485-490.

5. McClellan J, Kowatch R, Findling RL; Work Group on Quality Issues. Practice parameter for the assessment and treatment of children and adolescents with bipolar disorder. J Am Acad Child Adolesc Psychiatry 2007;46:107-125.

6. Smarty S, Findling RL. Psychopharmacology of pediatric bipolar disorder: a review. Psychopharmacology (Berl) 2007;191:39-54.

7. Pavuluri MN, Henry DB, Devineni B, Carbray JA, Naylor MW, Janicak PG. A pharmacotherapy algorithm for stabilization and maintenance of pediatric bipolar disorder. $J$ Am Acad Child Adolesc Psychiatry 2004;43:859-867.

8. Correll CU. Assessing and maximizing the safety and tolerability of antipsychotics used in the treatment of children and adolescents. J Clin Psychiatry 2008;69(Suppl 4):26-36.

9. Perlis RH, Welge JA, Vornik LA, Hirschfeld RM, Keck PE Jr. Atypical antipsychotics in the treatment of mania: a meta-analysis of randomized, placebo-controlled trials. $J$ Clin Psychiatry 2006;67:509-516.

10. Joshi G, Petty C, Wozniak J, Faraone SV, Doyle R, Georgiopoulos A, et al. A prospective open-label trial of quetiapine monotherapy in preschool and school age children with bipolar spectrum disorder. J Affect Disord 2012;136:1143-1153.

11. Barzman DH, DelBello MP, Kowatch RA, Gernert B, Fleck $\mathrm{DE}$, Pathak S, et al. The effectiveness and tolerability of aripiprazole for pediatric bipolar disorders: a retrospective chart review. J Child Adolesc Psychopharmacol 2004;14: 593-600.

12. Biederman J, McDonnell MA, Wozniak J, Spencer T, Aleardi M, Falzone R, et al. Aripiprazole in the treatment of pediatric bipolar disorder: a systematic chart review. CNS Spectr 2005;10:141-148.

13. Findling RL, Youngstrom EA, McNamara NK, Stansbrey RJ, Wynbrandt JL, Adegbite C, et al. Double-blind, randomized, placebo-controlled long-term maintenance study of aripiprazole in children with bipolar disorder. J Clin Psychiatry 2012;73:57-63.

14. Yoo HK, Choi SH, Park S, Wang HR, Hong JP, Kim CY. An open-label study of the efficacy and tolerability of aripiprazole for children and adolescents with tic disorders. J Clin Psychiatry 2007;68:1088-1093.

15. Kim JW, Park KH, Cheon KA, Kim BN, Cho SC, Hong $\mathrm{KE}$. The child behavior checklist together with the ADHD rating scale can diagnose ADHD in Korean communitybased samples. Can J Psychiatry 2005;50:802-805.

16. Conners CK, Barkley RA. Rating scales and checklists for child psychopharmacology. Psychopharmacol Bull 1985;21: 809-843.

17. Geller B, Tillman R, Bolhofner K, Zimerman B. Child bipolar I disorder: prospective continuity with adult bipolar I disorder; characteristics of second and third episodes; predictors of 8-year outcome. Arch Gen Psychiatry 2008;65: 1125-1133.

18. Duax JM, Youngstrom EA, Calabrese JR, Findling RL. Sex differences in pediatric bipolar disorder. J Clin Psychiatry 2007;68:1565-1573.

19. Escamilla I, Wozniak J, Soutullo CA, Gamazo-Garrán P, 
Figueroa-Quintana A, Biederman J. Pediatric bipolar disorder in a Spanish sample: results after 2.6years of follow-up. J Affect Disord 2011;132:270-274.

20. Kubacki A. Male and female mania. Can J Psychiatry 1986;31:70-72.

21. Wilens TE, Biederman J, Forkner P, Ditterline J, Morris M, Moore $\mathrm{H}$, et al. Patterns of comorbidity and dysfunction in clinically referred preschool and school-age children with bipolar disorder. J Child Adolesc Psychopharmacol 2003; 13:495-505.

22. Arnold LE, Demeter C, Mount K, Frazier TW, Youngstrom EA, Fristad M, et al. Pediatric bipolar spectrum disorder and ADHD: comparison and comorbidity in the LAMS clinical sample. Bipolar Disord 2011;13:509-521.
23. Joshi G, Biederman J, Wozniak J, Doyle R, Hammerness P, Galdo $\mathrm{M}$, et al. Response to second generation antipsychotics in youth with comorbid bipolar disorder and autism spectrum disorder. CNS Neurosci Ther 2012;18:28-33.

24. Zeni CP, Tramontina S, Ketzer CR, Pheula GF, Rohde LA. Methylphenidate combined with aripiprazole in children and adolescents with bipolar disorder and attention-deficit/hyperactivity disorder: a randomized crossover trial. J Child Adolesc Psychopharmacol 2009;19:553-561.

25. Marder SR, McQuade RD, Stock E, Kaplita S, Marcus R, Safferman AZ, et al. Aripiprazole in the treatment of schizophrenia: safety and tolerability in short-term, placebocontrolled trials. Schizophr Res 2003;61:123-136. 